\title{
Review of: "Forced Sliding Mode Control for Chaotic Systems Synchronization"
}

\author{
ANKIT SACHAN
}

Potential competing interests: The author(s) declared that no potential competing interests exist.

This paper poses a sliding mode control algorithm for synchronization of chaotic systems. The motivation and advantages of applying this new control algorithm is discussed over classical sliding mode but the novelty of the proposed control law is questionable.

More importantly, this paper is poorly written. The authors should write a paper by considering focus on the proposed control law instead of pre-existing technique. Its better to derive a theorem based on the findings for the proposed control law.

The explanation for the choosing this control law is not defined explicitly and much confusing.

Thus, I strongly recommend the author to give sufficient time in preparing this paper to make it more readable and understandable. 